\title{
Ability of Monaco shrimp Lysmata seticaudata (Decapoda: Hippolytidae) to control the pest glass anemone Aiptasia pallida (Actiniaria: Aiptasidae)
}

Received: 5 January 2004/ Revised: 22 June 2004 / Accepted: 4 November 2004/Published online: 18 January 2005

(c) Springer-Verlag and AWI 2005

\begin{abstract}
The present work highlights the ability of wild and cultured Monaco shrimp Lysmata seticaudata to control the glass anemone Aiptasia pallida. Starved shrimp ingested the highest percentages of glass anemones $[85.7 \%$ and $89.3 \%$ for wild (W) and cultured (C) shrimp, respectively]. The absence of symbiotic zooxanthellae in glass anemones did not influence the shrimps' feeding rate, with shrimp offered aposymbiotic anemones displaying the same feeding percentages (67.3\% and $70.7 \%$ for $\mathrm{W}$ and $\mathrm{C}$ shrimp, respectively) as those offered sea anemones with symbiotic zooxanthellae $(70.0 \%$ and $74.4 \%$ for $\mathrm{W}$ and $\mathrm{C}$ shrimp, respectively). Shrimp offered larger sea anemones had the lowest feeding percentages $(33.0 \%$ and $36.3 \%$ for $\mathrm{W}$ and C shrimp, respectively), along with shrimp offered an alternative food $(27.3 \%$ and $36.0 \%$ for $\mathrm{W}$ and $\mathrm{C}$ shrimp, respectively). There were no significant differences in the percentage of glass anemones ingested by cultured and wild Monaco shrimp in the same feeding trial.
\end{abstract}

Keywords Lysmata seticaudata · Monaco shrimp · Aiptasia pallida $\cdot$ Marine ornamentals .

Biological control

\section{Introduction}

The current trends in reef aquarium keeping promote the use of live rock to enhance biological filtration, a

Communicated by H.-D. Franke

R. Calado $(\bowtie) \cdot$ L. Narciso

Laboratório Marítimo da Guia,

Departamento de Biologia Animal,

Faculdade de Ciências da Universidade de

Lisboa. Forte Nossa Senhora da Guia,

Estrada do Guincho, 2750-642 Cascais, Portugal

E-mail: rjcalado@hotmail.com

Tel.: +351-214-869211

Fax: + 351-214-869720 simplified approach to create more natural living saltwater microcosms. The glass sea anemones of the genus Aiptasia are highly resistant organisms sometimes accidentally introduced in amateur and public reef aquariums with live rock. Due to the presence of zooxanthellae and their capacity for asexual reproduction by pedal laceration, these organisms are capable of quickly building huge populations, overgrowing display tanks and damaging highly priced species by allelopathy (Hunter 1984; Trench 1993). Biological control seems to be the best option to control Aiptasia outbreaks. It is recognised that the ornamental shrimps from the western Atlantic Lysmata rathbunae (Chace, 1970) and L. wurdemanni (Gibbes, 1850), commonly known as peppermint shrimp, effectively control glass anemones (Rhyne et al. 2004). Recent studies have highlighted the potential of the Monaco shrimp L. seticaudata (Risso, 1816), an eastern Atlantic related species, for the aquarium trade (Calado et al. 2003a). The ability of wild specimens to prey upon Aiptasia, while being reef-safe (not damaging other reef organisms), makes this shrimp an appealing species for the marine ornamentals industry. With the development of commercial culture methods for the Monaco shrimp (Calado et al. 2003b), it is important to experimentally evaluate whether captiveraised specimens also display the ability to control Aiptasia anemones. The present work compares the control effectiveness of Aiptasia pallida by wild and captive-raised shrimp during 48-h trials, evaluating the effects of shrimp starvation, food supply, anemone size and removal of symbiotic zooxanthellae from glass anemones.

\section{Methods}

Four A. pallida (Verril) were kept in a $30-1$ aquarium at $26^{\circ} \mathrm{C}, 35 \%$ salinity and an LD $12: 12$ photoperiod, in order to allow the symbiotic zooxanthellae to thrive. Anemones were fed on newly hatched Artemia nauplii and allowed to freely propagate asexually for 4 months. 
L. seticaudata shrimp were cultured as described by Calado et al. (2003b) and wild shrimp were collected from Cape Raso, $30 \mathrm{~km}$ west of Lisbon, using baited traps. Fifty cultured and 50 wild Monaco shrimp, with average total length (TL, distance between the rostrum anterior end and the telson posterior edge) ( \pm SD) of $35.0( \pm 2.5) \mathrm{mm}$ were haphazardly selected and kept separately in two 30-1 aquariums. Temperature, salinity and photoperiod were maintained as previously described for anemones. Both shrimp groups were fed about $10 \%$ their wet weight on a variety of commercial frozen foods before and between anemone feeding trials. Aiptasia control trials were performed in 3-1 plastic containers, with temperature and salinity kept at $26^{\circ} \mathrm{C}$ and $35 \%$, respectively. Glass anemones were carefully removed with a scalpel from the Aiptaisa stocking tank and ten of them (oral disk size ranging between 5 and $6 \mathrm{~mm}$ ) were placed inside each plastic container $2 \mathrm{~h}$ before each feeding trial. After this period, a single cultured or wild Monaco shrimp was added to each plastic container. Experiments were conducted as follows. (1) Control: fed cultured (C) and wild (W) shrimp were offered anemones (oral disk size between 5 and $6 \mathrm{~mm}$, containing symbiotic zooxanthellae) as the only food. (2) Starvation: C and W shrimp which had been starved for $48 \mathrm{~h}$ were offered anemones with the characteristics described in Control; (3) Alternative food: $\mathrm{C}$ and $\mathrm{W}$ shrimp were offered both anemones with the characteristics described in Control and mussel (Mytilus galloprovincialis) (10 pieces of about $4 \mathrm{~mm}^{3}$, the equivalent of $10 \%$ of shrimp wet weight, were placed inside the plastic containers); (4) Anemone size: C and W shrimp were offered anemones with the characteristics described in Control and anemones with oral disk size ranging between 9 and $10 \mathrm{~mm}$; and (5) $\mathrm{C}$ and $\mathrm{W}$ shrimp were offered sea anemones without zooxanthellae (anemones were placed in total darkness until their brownish coloration indicating the presence of symbiotic zooxanthellae was replaced by a whitish appearance, caused by the absence of symbiotic zooxanthellae). The number of glass anemones remaining in each plastic container was quantified $48 \mathrm{~h}$ after the beginning of each feeding trial. Sixty feeding trials $(30$ each for cultured and wild shrimp, respectively) were performed per experiment. A two-way analysis of variance was used to compare the feeding performance of $\mathrm{C}$ and $\mathrm{W}$ shrimp among the five different experiments, followed by Tukey's multiple comparisons test if significant differences were detected. The results were considered statistically significant at the 0.05 probability level (Zar 1996).

\section{Results}

Starved Monaco shrimp ingested a significantly higher percentage $(P<0.001)$ of Aiptasia $(85.7 \%$ and $89.3 \%$ for $\mathrm{W}$ and $\mathrm{C}$ shrimp, respectively), when compared with shrimp in other feeding experiments (Table 1). Shrimp in the control and those offered glass anemones without zooxanthellae ingested similar amounts $(P>0.91)$ of Aiptasia $(70.0 \%$ and $74.4 \%$ for $\mathrm{W}$ and $\mathrm{C}$ shrimp in the control, respectively; $67.3 \%$ and $70.7 \%$ for $\mathrm{W}$ and $\mathrm{C}$ shrimp offered aposymbiotic anemones, respectively), but displayed significantly higher $(P<0.0001)$ feeding percentages than those offered larger anemones and mussel pieces as an alternative food (Table 1). There was no significant difference $(P>0.83)$ between the percentages of anemones ingested by Monaco shrimp fed Aiptasia with oral disk diameters between 9 and $10 \mathrm{~mm}(33.0 \%$ and $36.3 \%$ for W and C shrimp, respectively) or those offered Aiptasia and mussel pieces $(27.3 \%$ and $36.0 \%$ for $\mathrm{W}$ and $\mathrm{C}$ shrimp, respectively) (Table 1).

There was no significant difference $(P>0.27)$ in the percentage of ingested Aiptasia between cultured and wild Monaco shrimp in the same feeding experiment (Table 1).

\section{Discussion}

The present experiments demonstrated that the efficiency of glass anemone control could be easily improved by simply starving the shrimp before their introduction into aquariums (e.g. during the quarantine period). The presence or absence of the symbiotic zooxanthellae does not seem to play a major role, since shrimp readily ingested symbiotic and aposymbiotic individuals. This is a relevant finding, since small aposymbiotic anemone pedal lacerates can give origin to new organisms (Clayton 1985). The fact that Monaco shrimp still continue to ingest, though in lower amounts, glass anemones when alternative foods are present is also an interesting finding, since the current microcosmos approach of reef aquariums present the inhabitants with a wide variety of food items. The

Table 1 Percentages of glass anemones A. pallida ingested by wild and cultured Monaco shrimp L. seticaudata under different experimental conditions

\begin{tabular}{llllll}
\hline & \multicolumn{2}{l}{ Percentage of ingested glass anemones (\%) } \\
\cline { 2 - 6 } & Control & Starvation & Alternative food & Anemone size & Zooxanthellae removed \\
\hline Wild Monaco shrimp & $70.0 \pm 15.1^{\mathrm{a}}$ & $85.7 \pm 11.7^{\mathrm{b}}$ & $27.3 \pm 13.6^{\mathrm{c}}$ & $33.0 \pm 11.5^{\mathrm{c}}$ & $67.3 \pm 14.4^{\mathrm{a}}$ \\
Cultured Monaco shrimp & $74.4 \pm 17.6^{\mathrm{a}}$ & $89.3 \pm 11.1^{\mathrm{b}}$ & $36.0 \pm 7.7^{\mathrm{c}}$ & $36.3 \pm 10.3^{\mathrm{c}}$ & $70.7 \pm 17.6^{\mathrm{a}}$ \\
\hline
\end{tabular}

Values are means $\pm \mathrm{SD}(n=30)$

Different superscript letters represent significant differences $(P<0.05)$ 
lower consumption rates of larger glass anemones can either be due to a faster shrimp satiation, with the ingestion of a lower number of Aiptasia, or by an increase in the number of nematocyst discharges from larger organisms, resulting in more powerful stings. An interesting observation has been recorded in preliminary trials where small groups of Monaco shrimp seemed to "cooperate" on the simultaneous "attack" of larger glass anemones, which were never approached by isolated shrimp. The present work clearly demonstrates that cultured Monaco shrimp are as efficient as wild ones in $A$. pallida control and should be preferred to other wild organisms.

Acknowledgements The authors would like to thank the Fundação para a Ciência e a Tecnologia (scholarship SFRH/BD/983/2000 and research project POCTI/BSE/43340/2001) from the Portuguese government for the financial support. We thank Ana Passos for allowing us to use her aquariums to conduct the experiments and Lueji Pestana for her help during wild shrimp collection and laboratory work. We would also like to express our sincere gratitude to Dr. Junda Lin for his valuable comments on the manuscript. We declare that the experiments performed in the present work comply with the current laws of the Portuguese Republic.

\section{References}

Calado R, Narciso L, Morais S, Rhyne AL, Lin J (2003a) Marine ornamental species - popular, pricey, and poorly studied. J Crust Biol 23:963-973

Calado R, Narciso L, Morais S, Rhyne AL, Lin J (2003b) A rearing system for the culture of ornamental decapod crustacean larvae. Aquaculture 218:329-339

Clayton Jr WS (1985) Pedal laceration by the anemone Aiptasia pallida. Mar Ecol Prog Ser 21:75-80

Hunter T (1984) The energetics of asexual reproduction: pedal laceration in the symbiotic sea anemone Aiptasia pulchella (Carlgren, 1943). J Exp Mar Biol Ecol 83:127-147

Rhyne AL, Lin J, Deal K (2004) Biological control of aquarium pest anemone Aiptasia pallida (Verrill) by peppermint shrimp Lysmata. J Shellfish Res 23:227-230

Trench RK (1993) Microalgal-invertebrate symbioses - a review. Endocytobiosis Cell Res 9:135-175

Zar JH (1996) Biostatistical analysis. Prentice Hall, Upper Saddle River, USA 